\title{
Extracts of Melia azedarach Increases Mulberry Whitefly Mortality without Affecting Silkworm Survivorship
}

\author{
Antonios E. Tsagkarakis ${ }^{1 *}$, Rodanthi Babili1 ${ }^{1}$ Paschalis Harizanis ${ }^{2}$, Dionyssios Ch. Perdikis ${ }^{1}$ \\ ${ }^{1}$ Laboratory of Agricultural Zoology and Entomology, Agricultural University of Athens, Athens, Greece \\ ${ }^{2}$ Laboratory of Sericulture and Apiculture, Agricultural University of Athens, Athens, Greece \\ Email: ^atsagarakis@aua.gr
}

How to cite this paper: Tsagkarakis, A.E. Babili, R., Harizanis, P. and Perdikis, D.Ch. (2016) Extracts of Melia azedarach Increases Mulberry Whitefly Mortality without Affecting Silkworm Survivorship. Advances in Entomology, 4, 293-298.

http://dx.doi.org/10.4236/ae.2016.45030

Received: October 10, 2016

Accepted: October 23, 2016

Published: October 27, 2016

Copyright $\odot 2016$ by authors and Scientific Research Publishing Inc. This work is licensed under the Creative Commons Attribution International License (CC BY 4.0).

http://creativecommons.org/licenses/by/4.0/ (c) (i) Open Access

\begin{abstract}
Melia azedarach L. extracts were studied in comparison with selected synthetic insecticides against the mulberry whiteflies Pealiusma chili and P. mori under laboratory conditions. Morus alba (cv. "Early Spring") leaves infested by mulberry whiteflies were exposed to Melia extracts of green fruits, l-cyhalothrin (10\% a.i.) and control. Also, white mulberry leaves after treatment with the same insecticides were provided to silkworms for consumption. Results have shown that there were significant differences in the nymphal mortality of the whiteflies among treatments. Melia extracts and l-cyhalothrin were effective in increasing whitefly mortality $24 \mathrm{~h}$ after application. Furthermore, Melia extracts didn't affect silkworm survivorship, which was severely affected by l-cyhalothrin treatment, since all the silkworms fed on treated leaves were found dead. Thus, these extracts might be considered a potential alternative in management of the mulberry whiteflies.
\end{abstract}

\section{Keywords}

Mulberry Whiteflies, Control, Melia azedarach, Extract, Silkworm

\section{Introduction}

Sericulture is the art of silk production, which comprises cultivation of mulberry, silkworm rearing and post cocoon activities leading to production of silk fiber. Due to the employment it provides, the economic development and the improvement in the quality of life to the people in rural area, it has great economic importance and, therefore, it plays an important role in anti-poverty program and prevents migration of rural people to urban area in search of employment [1]. 
Until today silk is considered one of the best and most expensive fabrics due to its fibers properties. The major silk producing countries in the world are China, India, Uzbekistan, Brazil, Thailand, Vietnam, Japan, etc. China and India are the main producer countries with more than $70 \%$ of the world's annual production [2].

Silkworms (Bombyx mori) are mainly monophagous, and they require white mulberry (Morus alba) leaves as a food source, in order to complete their immature life [3]. After the fourth molt, larvae prepare to enter the pupal stage and enclose themselves in a cocoon made of silk, from which the silk fiber is derived. If their diet does not include mulberry leaves, silkworms exhibit disrupted growth, high larval mortality, small and thin-walled cocoons, and adult deformities [4] [5].

Apart from silk, there are several other products from sericulture. The mulberry fruits are rich in minerals and vitamins and from the roots, barks and mulberry leaves several ayurvedic and herbal medicines are prepared. The mulberry branches after silkworm feeding are generally dried and used as fuel particularly in the villages. The foliage of mulberry is also used as a fodder for cattle [1].

Like many other crops worldwide, mulberry is affected by several genera of whiteflies [6] [7]. Whiteflies are tiny, phloem sap-sucking insects and, like aphids, they excrete sticky honeydew and cause yellowing or death of leaves. Whiteflies develop rapidly in warm weather, and populations can increase quickly when weather is favorable and natural enemies are absent [8]. In addition, whiteflies can transmit viruses to the plants they feed on, causing serious diseases.

Recently, three whitefly species infesting white mulberry were identified in Greece: Pealiusma chili (Takahashi), Pealius mori (Takahashi) and Paraleyrodes minei (Iaccarino) (Wang, J. R., D. Perdikis, C. Chalkia, P. Harizanis, A. Kalaitzaki, A. Tsagkarakis, Z. H. Xu and Y. Z. Du, unpublished data).

Management of heavy whitefly infestations is very difficult, since none of the insecticides is approved for use on mulberry in Greece. Furthermore, use of synthetic insecticides could damage silkworms fed on them. Thus, the effective control of whiteflies with organic insecticides, which can be used on mulberries without harming the silkworms feed on them later on, is of great importance.

As part of our ongoing research on natural insecticides, extracts from Melia azedarach were derived and tested on immatures of mulberry whiteflies. Thus, the purpose of the present research was to evaluate the effectiveness of these plant-derived extracts against mulberry whiteflies and their side effects on silkworms fed on treated mulberry leaves.

\section{Materials and Methods}

The experiment took place in laboratory conditions in the facilities of the Agricultural University of Athens (AUA), Greece, in July 2016.

\subsection{Whitefly Mortality}

In the first part of the experiment, the effect of plant extracts on the mortality of mul- 
berry whiteflies was studied. For this reason, leaves from white mulberry trees (cv. "Early Spring") infested by whiteflies were collected from the experimental orchard of the AUA campus and transported to the laboratory. Under a binocular microscope, the number of whitefly nymphs of each leaf was recorded. On the observed leaves, nymphs from only P. machili and P. mori were found. As for the identification, it was accomplished through referring to the literature of all the species of this genus and it was confirmed by J.-R. Wang (Wang, J. R., D. Perdikis, C. Chalkia, P. Harizanis, A. Kalaitzaki, A. Tsagkarakis, Z. H. Xu and Y. Z. Du, unpublished data). Then, leaves were divided in groups of five and treated with extracts of $M$. azedarach green fruits in a rate of $5 \mathrm{ml} / \mathrm{L}$. The extracts were prepared after green fruits $10 \% \mathrm{w} / \mathrm{w}$ was placed in glycerol/water system with $1 \%$ microcare SB (potassium sorbate + sodium benzoate) as a preservative and $0.4 \%$ citric acid as an acidifier. Wetting lasted 14 days and then was filtered by bag filters $25 \mu \mathrm{m}$. Furthermore, a group of leaves was treated with 1-cyhalothrin (Karate ${ }^{\circledR}$ Zeon $^{\circledR} 10 \mathrm{CS}$ ) with a rate of $0.125 \mathrm{cc} / \mathrm{L}$ (label rate for sucking mouthpart insects) and another one remained untreated and served as control. All products were applied as foliar sprays to runoff, coating upper and lower leaf surfaces, using a 1-L handheld pumpup sprayer. Lamda-cyhalothrin application rate was selected based on the recommended label rate for tree use against whiteflies. Then, each leaf was placed individually in a petri dish supported by placing the leaf on a thin layer of damp cotton, which was slightly folded to cover a part of the leaf stem. The dishes were kept in room condition $\left(25^{\circ} \mathrm{C} \pm 5^{\circ} \mathrm{C}, 60 \% \pm 5 \%\right.$ r.h. and 14L:10D h photoperiod). Twenty-four hours later, each leaf was examined again under a binocular microscope and the number of live and dead whitefly nymphs was recorded. Mortality of nymphs was assessed by dividing the number of dead nymphs by the total number of nymphs per leaf. The experimental procedure repeated three times.

\subsection{Silkworm Survivorship}

The second part of the experiment was about the side effects of the plant extracts on silkworms. Leaves from white mulberry trees (cv. "Early Spring") were collected and treated with insecticides, exactly as in the first partof the experiment. Each group contained 10 treated leaves, which were placed in a closed carton box $\left(20 \times 30 \times 10 \mathrm{~cm}^{3}\right)$ and 10 silkworms $\left(1-3^{\text {rd }}\right.$ instar) were inserted. The boxes were kept in room condition $\left(25^{\circ} \mathrm{C} \pm 5^{\circ} \mathrm{C}, 60 \% \pm 5 \%\right.$ r.h. and $14 \mathrm{~L}: 10 \mathrm{D}$ h photoperiod). Twenty-four hours later, boxes were opened and the number of live and dead silkworms was recorded. Mortality of silkworms was assessed by dividing the number of dead by the total number of silkworms per box. The experimental procedure repeated three times.

\subsection{Statistical Analyses}

Whitefly and silkworm mortality were arcsine-transformed to ensure normality, linearity, and homoscedasticity. Differences between treatment means were tested for significance with Tukey's honestly significant difference $(H S D)$ test $(P=0.05)$. All analyses were conducted using JMP [9]. 


\section{Results}

\subsection{Whitefly Mortality}

Results showed significant differences in whitefly nymphal mortality between the treatments $\left(\mathrm{F}_{2,87}=48.36, \mathrm{P}<0.001\right)$. Melia azedarach extract caused significantly higher mulberry whitefly mortality $(25.59 \% \pm 1.92 \%)$, compared with the untreated control $(20.35 \% \pm 3.03 \%)$ (Figure 1$)$. Although, mortality caused by $M$. azedarach was significantly lower than 1-cyhalothrin's, which reached $42.04 \% \pm 2.11 \%$ ) (Figure 1).

\subsection{Silkworm Survivorship}

While the application of Melia azedarach extract was effective on mulberry whitefly mortality, no side effect on silkworms was observed, since all the silkworms were found alive and active (Figure 2). On the contrary, all the silkworms kept on leaves treated with 1-cyhalothrin were found dead $24 \mathrm{~h}$ after encaging (Figure 2).

\section{Discussion}

Generally, $M$. azedarach fruit extracts applied to the plant surface have toxic and repellent effect against the whiteflies, Bemisia argentifolii Bellows \& Perring (Homoptera: Aleyrodidae) and B. tabaci (Gennadius) (Homoptera: Aleyrodidae), respectively [10] [11] [12]. Results of the present experiment verifies the aforementioned experiments. Increase of the mortality of the nymphs of the mulberry whiteflies, $P$. machili and $P$. mori, compared with the untreated control indicate that most probably toxic effects of Melia extracts accounted. Mortality of mulberry whiteflies was significantly lower than 1-cyhalothrin, which although was expected.

In the second part of the experiment, results showed that the toxic effects of Melia

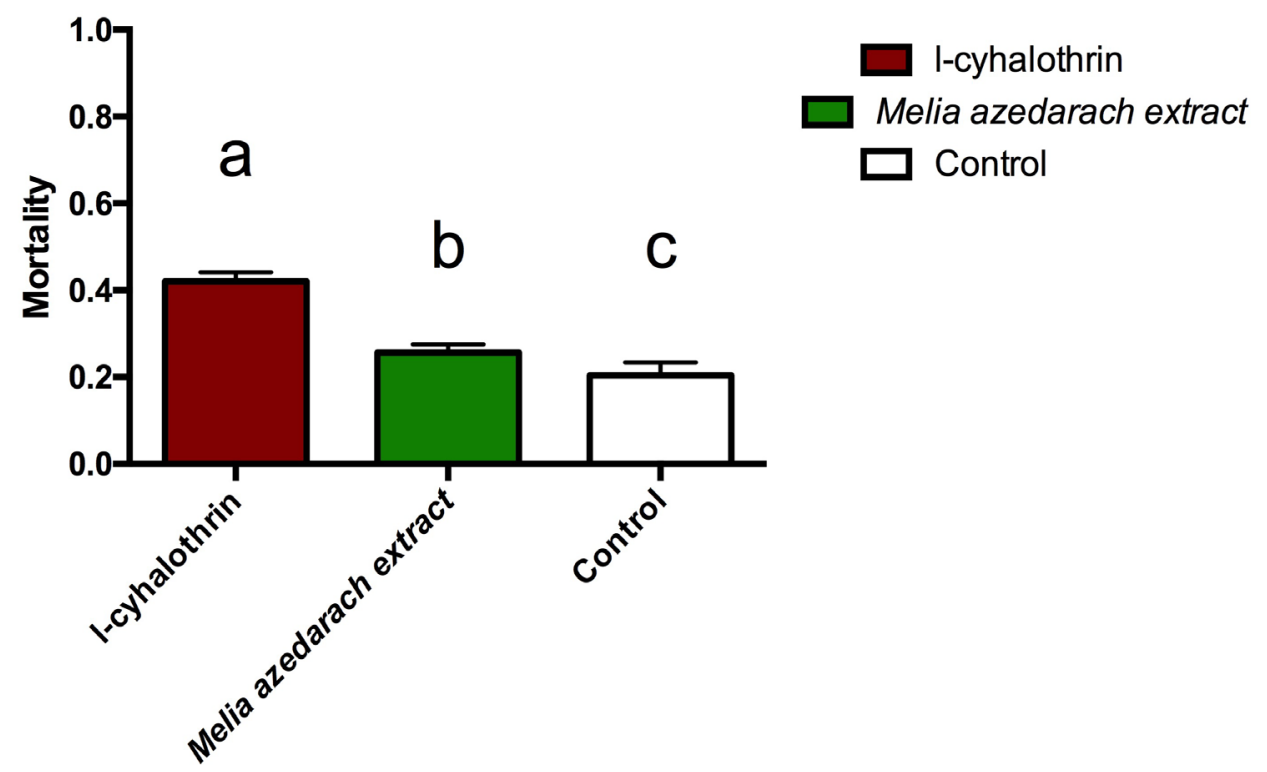

Figure 1. Nymphal mortality of mulberry whiteflies Pealius machili and P. moriafter insecticide foliar application in laboratory conditions (columns without common letter differ statistically). 


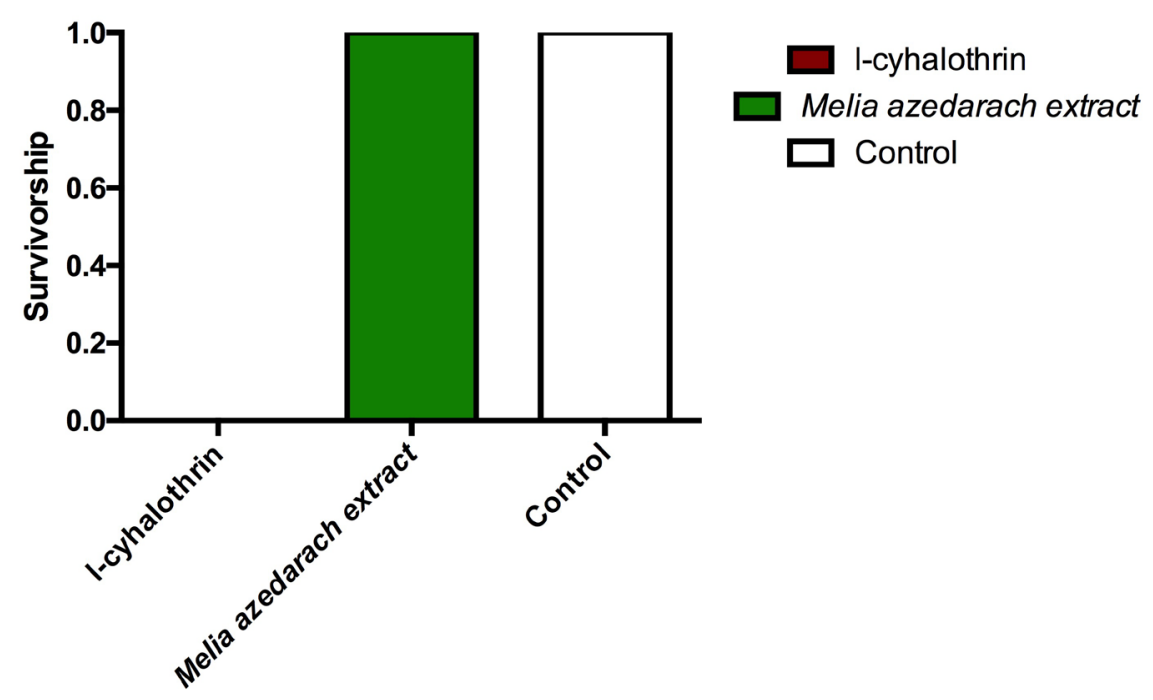

Figure 2. Silkworm survivorship after feeding with white mulberry leaves treated with insecticides in laboratory conditions.

extracts did not affect the silkworm survivorship after consuming treated leaves. Although, Melia extracts have showed several effects when applied against other insects. Specifically, decrease of population of the citrus leafminer, Phyllocnistis citrella Stainton (Lepidoptera: Gracilariidae), occurred after application of Melia extracts [13]. Also, population decrease of the pea leafminer, Liriomyza huidobrensis (Blanchard) (Diptera: Agromyzidae), on swisschard and cucumber plants, as well as the vegetable leafminer, L. sativae Blanchard (Diptera: Agromyzidae), on cowpea plants, has been observed [14]. This difference most probably occurred because of the significantly larger body mass of the silkworm compared with the leafminers.

\section{Conclusion}

In conclusion, the present study showed that $M$. azedarach extracts clearly had adverse effects on mulberry whiteflies $P$. machili and $P$. mori, by increasing the nymphal mortality when sprayed on mulberry leaves, in laboratory conditions. Also, no negative effect on silkworm survivorship when fed with treated leaves was observed. However, these results are not sufficient to assess whether the achieved effects of Melia ingredients provide an economically relevant protection of mulberry trees from damage by this pest species. Further experiments in the orchard are needed in order to test the efficacy of Melia extracts in real conditions. Also, these extracts are potentially promising methods to be used in sustainable agriculture approaches against the mulberry whiteflies and they have to be tested for their effects on the biological control agents of these pests. Beyond this, the results of this study encourage to test effects of Melia extracts on other pests of mulberry and other tree species.

\section{Acknowledgements}

The authors would like to thank Mrs. Zoe Thanou for the technical support in spraying 
applications.

\section{References}

[1] FAO (2016) Conservation Status of Sericulture Germplasm Resources in the World. http://www.fao.org/docrep/005/ad108e/ad108e0a.htm

[2] ISC (2016) Statistics of International Sericultural Commission. http://inserco.org/en/?q=statistics

[3] Ombrello, T. (2012) The Mulberry Tree and Its Silkworm Connection. Ph.D. Thesis, Union County College, Cranford.

[4] Dadd, R.H. (1973) Insect Nutrition: Current Developments and Metabolic Implications. Annual Review of Entomology, 18, 381-420. http://dx.doi.org/10.1146/annurev.en.18.010173.002121

[5] Kanekatsu, R., Kitagawa, R. and Yanagisawa, Y. (1991) Using Semisynthetic Diets. Journal of Sericultural Science of Japan, 60, 55-62.

[6] Martin, J.H. (1987) An Identification Guide to Common Whitefly Pest Species of the World (Homoptera, Aleyrodidae). Tropical Pest Management, 33, 298-322.

http://dx.doi.org/10.1080/09670878709371174

[7] Martin, J.H., Mifsud, D. and Rapisarda, C. (2000) The Whiteflies (Hemiptera: Aleyrodidae) of Europe and the Mediterranean Basin. Bulletin of Entomological Research, 90, 407-448. http://dx.doi.org/10.1017/s0007485300000547

[8] Bureekham, I., Chareonsom, K., Sayampol, B., Aukarathanakul, P., Suasaad, V., Amornsak, V. and Kantaratanakul, S. (1987) Laboratory Practice in Agricultural Entomology. Kasetsart University Press, Bangkok.

[9] SAS Institute (2011) JMP ${ }^{\circledR} 10.0$ User Guide. 2nd Edition, SAS Institute Inc., Cary.

[10] Abou-FakhrHammad, E. and McAuslane, H. (2006) Effect of Melia azedarach L. Extract on Bemisia argentifolii (Homoptera: Aleyrodidae) and Its Biocontrol Agent Eretmocerus rui (Hymenoptera: Aphelinidae). Environmental Entomology, 35, 740-745. http://dx.doi.org/10.1603/0046-225X-35.3.740

[11] Abou-Fakhr Hammad, E.M., Nemer, N.M., Hawi, Z.K. and Hanna, L.T. (2000) Responses of the Sweetpotato Whitefly, Bemisia tabaci, to the Chinaberry Tree (Melia azedarach L.) and Its Extracts. Annals of Applied Biology, 137, 79-88. http://dx.doi.org/10.1111/j.1744-7348.2000.tb00039.x

[12] Abou-Fakhr Hammad, E.M., Zournajian, H. and Talhouk, S. (2001) Efficacy of Extracts of Melia azedarach L. Callus, Leaves and Fruits against Adults of the Sweetpotato Whitefly Bemisia tabaci (Hom. Aleyrodidae). Journal of Applied Entomology, 125, 483-488. http://dx.doi.org/10.1046/j.1439-0418.2001.00577.x

[13] Mckenna, M.M., Abou-Fakhr Hammad, E.M. and Farran, M. (2013) Effect of Melia azedarach (Sapindales: Meliaceae) Fruit Extracts on Citrus Leafminer Phyllocnistiscitrella (Lepidoptera: Gracillariidae). SpringerPlus, 2, 144.

[14] Abou-Fakhr Hammad, E. and McAuslane, H. (2010) Effect of Melia azedarach L. Extract on Liriomyza sativae (Diptera: Agromyzidae) and Its Biocontrol Agent Diglyphus isaea (Hymenoptera: Eulophidae). Journal of Food, Agriculture \& Environment, 8, 1247-1252. 